\title{
Photodegradation Behaviour of Nitrogen-Containing Graphene Derivatives Towards Pollutant Dyes and Real- TimeAssessment on Aquatic Weed
}

\author{
Peetam Mandal $^{1}$ (D), Mitali Saha ${ }^{1, *(D)}$ \\ 1 Department of Chemistry, National Institute of Technology Agartala, Tripura - 799046, India \\ * Correspondence: mitalichem71@gmail.com(M.S.);
}

Scopus Author ID 55779373600

Received: 22.06.2021; Revised: 28.07.2021; Accepted: 2.08.2021; Published: 15.08.2021

\begin{abstract}
Discharge of dyes in the aquatic system is ubiquitous environmental chaos, and combating this particular anthropogenic issue with graphene-based materials via photodegradation process has been a radiant approach in recent times. In this work, 3-aminophenol produced nanosheets of $\mathrm{N}$ graphene (NG) in the presence of urea in a single step at a relatively low temperature of $\sim 120-125^{\circ} \mathrm{C}$ in contrast to nitrogen-containing graphene oxide (NGO) produced in the absence of urea. The V-shape of urea facilitated the formation of a poly-hexagonal array of rings and prevented the attack of oxygen at normal atmospheric conditions. During the comparison of the photodegradation ability of both NG and NGO against MG, MB, and MO, the degradation efficiency was found to be $92-99 \%$. Further LCMS/MS studies proved that NGO was capable of mineralizing the complex structures of the dyes via the demethylation route initially followed by asymmetric cleaving at neutral $\mathrm{pH}$. The in-vitro real-time application of an aquatic weed (Lemna minor) was also compared against the 1:1:1 ratio of MG, MB, $\mathrm{MO}$, and NGO-treated dye water. No substantial growth of Lemna minor was found in the case of using the dye mixture even up to the 20th day, whereas rapid growth of this aquatic weed was observed within 15 days in the case of NGO treated dye mixture.
\end{abstract}

Keywords: $\mathrm{N}$ - graphene; Lemna minor; photodegradation; malachite green; methyl orange; methylene blue.

(C) 2021 by the authors. This article is an open-access article distributed under the terms and conditions of the Creative Commons Attribution (CC BY) license (https://creativecommons.org/licenses/by/4.0/).

\section{Introduction}

Due to sprawling industrialization and lack of stringent quality control policies against the discharge of dye pollutants into wastewater bodies in developing nations, water pollution has become an appalling scenario in the last few decades [1-3]. Amongst various pollutant dyes, malachite green (MG), methylene blue (MB), and methyl orange (MO) impose a carcinogenic threat on human activities and aquatic life as well as hinder the $\mathrm{pH}, \mathrm{DO}, \mathrm{BOD}$, COD, and turbidity level of water drastically [4-9]. Ecotoxicological studies revealed that the presence of aromatic rings, heteroatoms $(\mathrm{S}, \mathrm{Cl}, \mathrm{N})$, multiple functional groups $\left(-\mathrm{OH},-\mathrm{R}_{3} \mathrm{~N}\right.$, $\mathrm{R}-\mathrm{O}-\mathrm{SO}_{3}{ }^{-}$, etc., $), \sigma$ bonds coupled to aromatic rings, low heat of formation $\left(\Delta \mathrm{H}_{\mathrm{f}}\right)$, and high resonance make the structure of these dyes highly stable and soluble in almost every solvent and hazardous for the terrestrial and aquatic environments. The photodegradation process was instrumental in countering dyes, heavy metals, and pesticides, relinquishing the need for additional energy input [10-15]. The well-established chemical insight of functionalized graphene had played a pivotal role as an adsorbent, photocatalyst, sensing, biological system, 
and scavenging pollutant compounds [16-25]. 3-aminophenol, which was earlier converted into nanosheets of nitrogen-containing graphene oxide (NGO) at the relatively low temperature of $\sim 120-125^{\circ} \mathrm{C}$ without the use of an oxidizing agent [26], was also found to produce nanosheets of $\mathrm{N}$-graphene in the presence of urea in a single step at the same temperature. In the present work, it was observed that the $\mathrm{V}$-shape of urea facilitated the development of a poly-hexagonal array of rings and prevented the attack of oxygen at normal atmospheric conditions. The photodegradation ability of NGO was compared with $\mathrm{N}$-graphene towards $\mathrm{MG}, \mathrm{MB}, \mathrm{MO}$, along with their mixture. The in-vitro real-time application was also executed by comparing the sustainable growth of Common Duckweed (Lemna minor) in the presence of NGO, and Ngraphene treated water.

\section{Experimental}

\subsection{Materials and methods.}

Urea and 3-aminophenol were purchased from HiMedia Laboratories (Molecular Biology Grade) and Merck (MQ-400 grade), respectively. Malachite green (MG), methylene blue (MB), and methyl orange (MO) were bought from Alfa Aesar. EMSURE® Reag. Ph Eur,ISO grade Nitric acid was used for purification of the synthesized materials. Powder Xray Diffraction (XRD) patterns were collected on a Bruker D8 Advance diffractometer using $\mathrm{Cu} \mathrm{K} \alpha$ radiation $(\lambda=1.5418 \AA)$. The diffraction patterns in the $10-60^{\circ}(2 \theta)$ region were recorded at room temperature with a scanning step size of $0.04^{\circ}(2 \theta)$ per second. The optical properties were investigated at $25^{\circ} \mathrm{C}$ using Renishaw inVia ${ }^{\mathrm{TM}}$ confocal Raman microscope with $514 \mathrm{~nm}$ laser exciton, and the spectral range was $1000-3000 \mathrm{~cm}^{-1}$. High-Resolution Transmission Electron Microscopy (HRTEM) micrographs and their corresponding High Angle Annular Dark Field-Scanning Transmission Electron Microscopy (HAADF-STEM) images were analyzed in JEM-2100F field emission gun microscope at an acceleration voltage of $300 \mathrm{kV}$. The samples were dispersed in iso-propanol at room temperature before mounting on lacey carbon formvar coated $\mathrm{Cu}$ grid while Electron Dispersive X-ray (EDX) was performed using an X-Max ${ }^{\mathrm{N}}$ 65T detector. X-ray Photo-electron Spectroscopy (XPS) spectrum was obtained from Escalab 250Xi spectrophotometer having $\mathrm{Al} \mathrm{K} \alpha$ emission source.The absorbance spectra and their corresponding relative dye content was calculated using Cary 60 | Agilent Technologies UV-Vis spectrophotometer at a scan range of 200-800 nm. A Waters Alliance ${ }^{\circledR}$ HPLC with e2695 separation module coupled with 2998 PDA detector was used for the analysis of three dyes following the operational parameters; Mobile phase: $\mathrm{B}, 0.1 \%$ phosphoric acid in acetonitrile, $\mathrm{C}, 0.1 \%$ phosphoric acid in the water, flow rate: $1 \mathrm{ml}$ per min, Column: RPC18 Agilent made, $\lambda$ : $620 \mathrm{~nm}$ for MG, $662 \mathrm{~nm}$ for MB, $503 \mathrm{~nm}$ for MO. The gradient program was as follows: $0-4 \mathrm{~min} @ 1 \mathrm{ml}$ per min flow rate with $\mathrm{B}-40 \%$ and $\mathrm{C}-$ $60 \%$, then $4-4.5 \min \mathrm{B}-60 \%$ and $\mathrm{C}-40 \%, 4.5-8 \min \mathrm{B}-60 \%$ and $\mathrm{C}-40 \%$, then $8-9$ $\min \mathrm{B}-60 \%$ and $\mathrm{C}-60 \%$ and finally run from $9-15$ min with $\mathrm{B}-40 \%$ and $\mathrm{C}-60 \%$. The HPLC separation was coupled with AB Sciex Triple Quad 5500, Agilent Technologies mass spectrometer. The spectrometer was equipped with an electrospray ionization (ESI) source and functioned at both positive and negative polarity. The ESI conditions were customized as follows: capillary voltage: $5.5 \mathrm{kV}$ in positive and $-4.5 \mathrm{kV}$ in negative, nebulizer pressure at 70 psi while the mass range was from 50 to $600 \mathrm{Da}$. 
2.2. One-step synthesis of nitrogen-containing graphene oxide (NGO) and $N$-graphene (NG).

3-aminophenol was subjected to heat treatment at its melting temperature $(\sim 120-$ $125^{\circ} \mathrm{C}$ ) for $4 \mathrm{~h}$ in trace air, resulting in the formation of dull brownish-black colored nitrogencontaining graphene oxide (NGO) reported earlier [26]. When the same precursor was heated in the presence of urea (1:5 wt. ratio) at the same temperature, it formed a shiny black-colored product after $4 \mathrm{~h}(\mathrm{NG})$. The resulted material was washed thoroughly with deionized water and dried in a vacuum oven overnight.

\subsection{Photodegradation studies under visible light illumination.}

The photodegradation ability of both NGO and NG were studied against three pollutant dyes viz., MG, MB, and MO under the illumination of a commercial 40-Watt Wipro LED lamp. $100 \mathrm{ppm}$ aqueous solution of each dye was prepared, separately followed by the addition of NGO and NG (100 mg each) as demonstrated in Scheme 1.

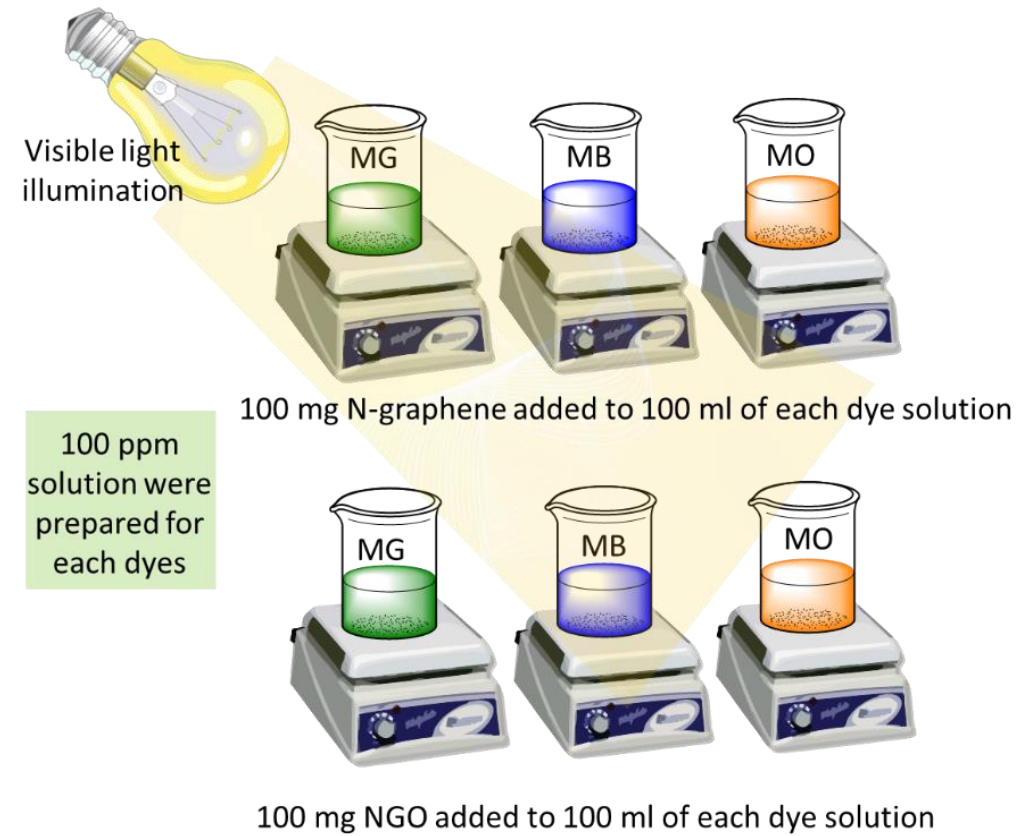

Scheme 1. Photodegradation reaction of NGO and NG.

A mixture of MG, MB, and MO (1:1:1) was also prepared to study the adsorption efficiency and photodegrading ability of NGO. The absorbance spectra and their corresponding relative dye content was observed in UV-Vis spectrophotometer. To study the kinetics and photodegradation efficiency, the solutions obtained after photodegradation against each dye werepassed through HPLC column, and retention time was studied and compared with the standard stock solutions of dyes. The retention time (r.t.) of standard MG, MB, and MO solutions were found to be $8.628,3.701$, and $4.567 \mathrm{mins}$, respectively.

\subsection{Real-time application of dye mixture and dye treated water with NGO.}

The standard dye mixture and the photodegraded water using NGO were utilized to study the in-vitro growth of Common Duckweed (Lemna minor). Lemna minor was obtained from a local freshwater lake: Dimsagar lake, Agartala, Tripura, India $\left(23.8398589^{\circ} \mathrm{N}\right.$, $\left.91.2816976^{\circ} \mathrm{E}\right)$.

\section{Results and Discussion}




\subsection{Nitrogen-containing graphene oxide $(N G O)$ and graphene $(N G)$.}

3-aminophenol was found to produce NGO in the presence of trace amount of air and NG in the presence of urea at the same temperature, which indicated that its aromatic structure actively participated in the aromatization, whereas the $\mathrm{V}$-structure of urea facilitated the cyclization and also prevented the attack of atmospheric oxygen during the formation of NG. The diffractogram patterns of NG demonstrated the 002 planes at $2 \theta=22.01^{\circ}$, which revealed the formation of graphene structure (Figure 1a). The Raman spectral analysis of NG exhibited a D - band at $\sim 1367 \mathrm{~cm}^{-1}$, attributing to the out-of-plane structural defects on the edge of the graphene structure (Figure 1b).
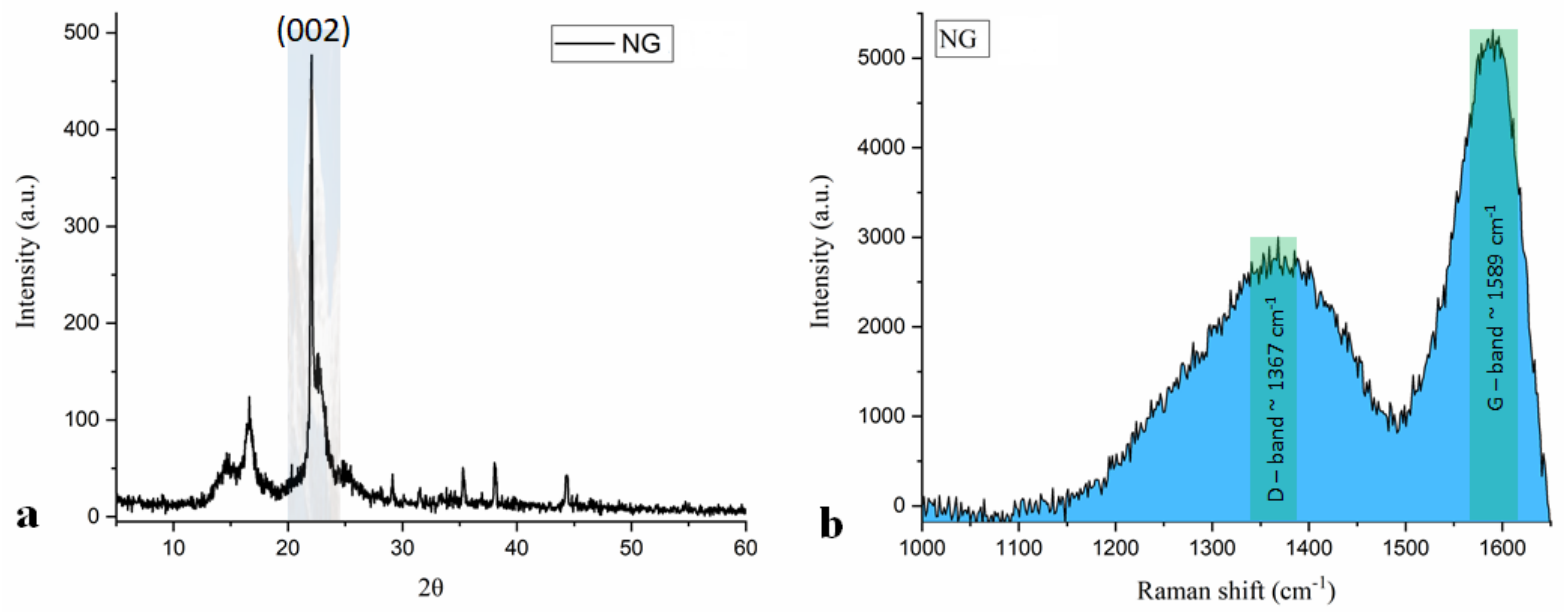

Figure 1. (a) XRD pattern; (b) Raman spectral analysis of NG.
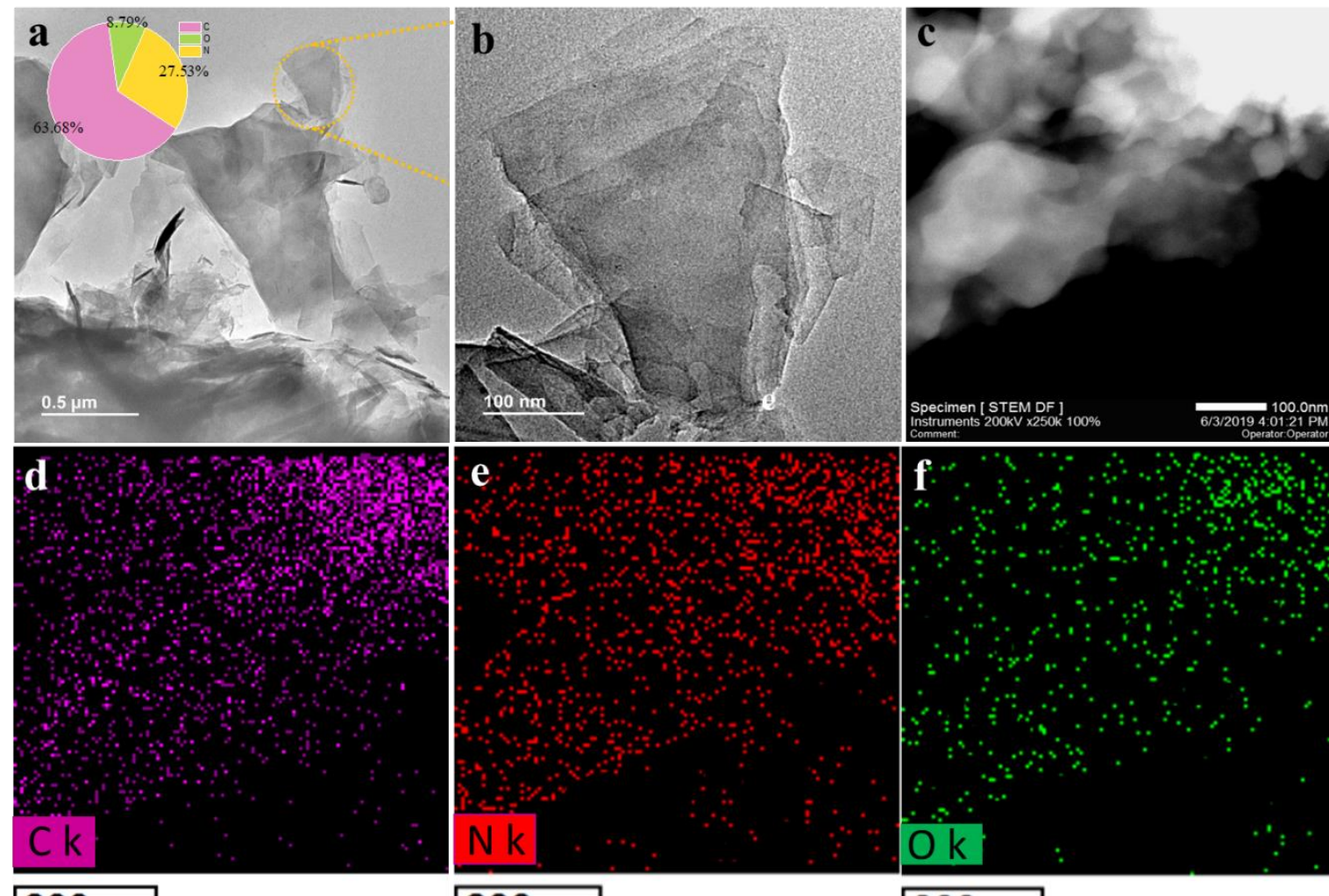

$200 \mathrm{~nm}$

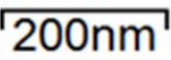

$200 \mathrm{~nm}$

Figure 2. TEM of (a, b) NG (inset) and its corresponding EDX pie-chart (c) HAADF-STEM of NG and its corresponding elemental mapping (d) carbon (e) nitrogen and (f) oxygen.

It also confirmed the lattice distortions in the basal plane of NG [27]. The $\mathrm{G}-$ band observed at $\sim 1589 \mathrm{~cm}^{-1}$ was much more intense and sharper than the respective D - band, 
which suggested forming an $\mathrm{sp}^{2} \mathrm{C}-\mathrm{C}$ hybridized state of $\mathrm{C}-\mathrm{C}$ stretching within the polyhexagonal arrangement of the $\mathrm{NG}$ plane. The calculated $\mathrm{I}_{\mathrm{D}} / \mathrm{I}_{\mathrm{G}}$ ratio of $\mathrm{NG}$ was found to be 0.55 , indicating the formation of few layers only with fewer defects within the graphene lattice [28, 29]. The estimation of $I_{D} / I_{G}$ ratio further assisted in measuring the domain size upon incorporating Tuinstra-Koenig relation [30].

$$
L_{\alpha}(n m)=\frac{\left(2.4 \times 10^{-10}\right) \lambda_{\text {laser }}^{4}}{\left(\frac{I_{D}}{I_{G}}\right)}-(1)
$$

where $I_{D}$ and $I_{G}$ represented the intensity of the $D$ - band and $G$ - band, respectively, $\lambda_{\text {laser }}$ is the wavelength of laser exciton, and L $\alpha$ is the crystallite domain size of the NG. The calculated domain size of NG was found to be $\sim 30.45 \mathrm{~nm}$.

The TEM images of NG, its corresponding HAADF-STEM, and elemental mapping displayed the structural morphology, elemental distribution, and formation of nanosheets with an average size $\sim 150-170 \mathrm{~nm}$ (Figure 2a-f). The EDX represented the pie-chart with high nitrogen content $\sim 27 \%$ (Figure $2 \mathrm{a}$, inset). It further confirmed the homogeneous distribution of nitrogen across the graphenic plane (Figure $2 \mathrm{~d}-\mathrm{f}$ ).

$\mathrm{X}$-ray Photo-electron Spectroscopy (XPS) images indicated 4 major peaks of $\mathrm{C} 1 \mathrm{~s}$ viz. $287.38 \mathrm{eV}(\mathrm{C}=\mathrm{O}), 286.56 \mathrm{eV}\left(\mathrm{sp}^{2} \mathrm{C}=\mathrm{N}\right), 286.19 \mathrm{eV}\left(\mathrm{sp}^{3} \mathrm{C}-\mathrm{N}\right)$ and $284.92 \mathrm{eV}\left(\mathrm{sp}^{2} \mathrm{C}=\mathrm{C}\right)$ as per XPS reference spectrum in case of NG (Figure 3a) [31]. This suggested that carbon was mostly attached to nitrogen atoms via $\mathrm{sp}^{2}$ hybridization within the graphene sheets, giving clear evidence of the presence of nitrogen within the lattice of the aromatic rings. The mixture of $\mathrm{sp}^{3}$ and $\mathrm{sp}^{2}$ hybridization of the carbon atoms also indicated the formation of graphenic structures within the sheets. Figure $3 \mathrm{~b}$ demonstrated N-1s $\sim 401.74 \mathrm{eV}$, split into three major groups on the basis of their linkages i.e., $403.48 \mathrm{eV}$ (pyridinic $-\mathrm{N}), 401.48 \mathrm{eV}($ graphitic $-\mathrm{N}$ ) and 399.38 $\mathrm{eV}($ pyrrolic $-\mathrm{N}$ ). The deconvolution of nitrogen highlighted a larger portion of graphitic nitrogen than pyrrolic and pyridinic nitrogen in the XPS data. This concluded that nitrogen was present mostly inside the poly-hexagonal rings of the graphitic plane than on the edges.
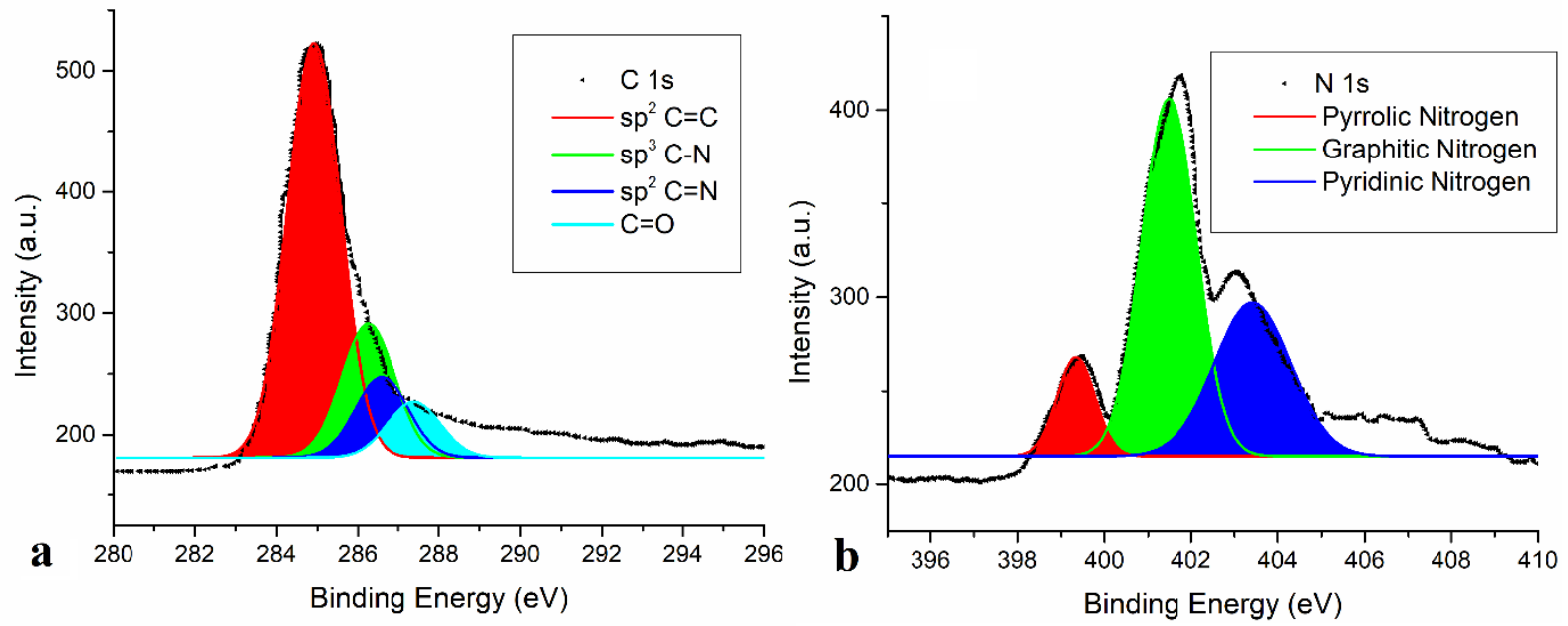

Figure 3. High-resolution XPS spectrum of NG, (a) Carbon 1s and (b) Nitrogen 1s.

The mechanism behind the direct conversion of 3-aminophenol into NG in the presence of urea indicated the involvement of the aromatic nature of 3-aminophenol in further condensation, cyclization, and aromatization without the use of nitrogen doping agents (Figure 4). 


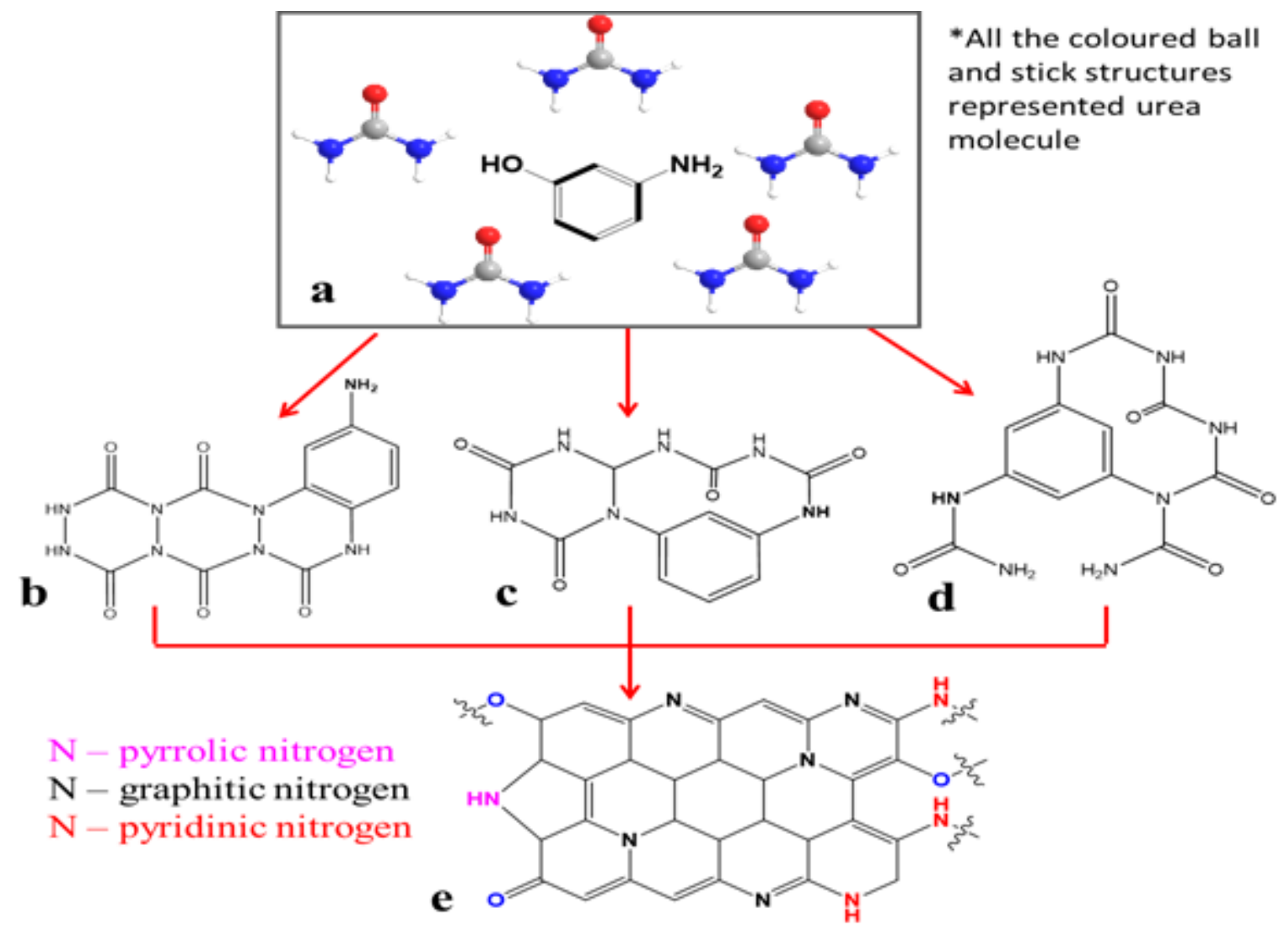

Figure 4. Proposed mechanism of the formation of one-step N-graphene (a) reaction initiation of 1:5 ratio of 3aminophenol and urea. $(b-d)$ possible intermediates formed from adjoining urea with 3-aminophenol (e) $\mathrm{N}$ graphene formed after 4 hours of heating at $120-125^{\circ} \mathrm{C}$, i.e., $\mathrm{NG}$.

The V-shaped urea also participated in the cyclization to form six-membered rings under a prolonged heating environment. The possibility of delocalization in double bonds was greatly initiated by the linkages between urea and 3-aminophenol, favoring the formation of few-layered nanosheets of NG. The two $-\mathrm{NH}_{2}$ groups of urea helped in the hexagonal ring formation as well as prevented the attack of atmospheric oxygen addition in NG. It was quite predictable that the terminal nitrogen in 3-aminophenol and nitrogen atoms in hygroscopic urea easily escaped from the reaction as an ammonia by-product during heat treatment while condensation might have occurred simultaneously.

\subsection{Photodegradation process under commercial visible light illumination.}

It is well established that functionalized graphene derivatives are found to be more effective in photodegradation against pollutant dyes due to $\pi$-conjugated network, facilitating exciton separation and high electron mobility [8, 16, 17, 32-34]. It was observed that both NG and NGO were found to show equivalent efficiency towards MG, MB, and MO during photodegradation. The comparative photodegrading performances of NG and NGO were executed against pollutant dyes viz. MG, MB, and MO under commercial 40-Watt Wipro LED lamp at room temperature $\sim 25^{\circ} \mathrm{C}$. In the case of a 100-ppm concentration of MG, the NG and NGO gave the absorbance spectra showing a gradual decline over the irradiation period (Figure $5 a)$. In the presence of non-functionalized graphene (NG), around 50\% of MG was degraded within a span of 15 mins, and $\sim 92.1 \%$ was found to degrade after $7 \mathrm{~h}$ of irradiation under visible light. Whereas in the presence of nitrogen-containing graphene oxide (NGO), the absorbance peak showed a steep decline within 5 mins (Figure 5b). This highlighted that NGO 
could drastically degrade the dye $\sim 92.1 \%$ within 5 mins, which reached a threshold value of $\sim$ $95 \%$ after $7 \mathrm{~h}$ (Figure 5c).

The increased efficiency of non-functionalized NG towards photodegradation of MG indicated that the presence of nitrogen within the graphenic lattice and $\mathrm{C}=\mathrm{O}$ groups in the side edges facilitated the electron mobility and exciton separation. Similarly, the presence of -OH, $-\mathrm{NH}_{2}, \mathrm{C}=\mathrm{O}$ groups present in $\mathrm{NGO}$ enhanced the rate of MG's photodegradation compared to NG. In contrast to the degradation ability of NG and NGO under visible light, these materials could not harvest any effective degradation results in the dark condition against MG. The relative peak area was calculated using an HPLC chromatogram with the usage of NG and NGO, correspondingly (Figure 5d, e).

$\mathbf{a}$
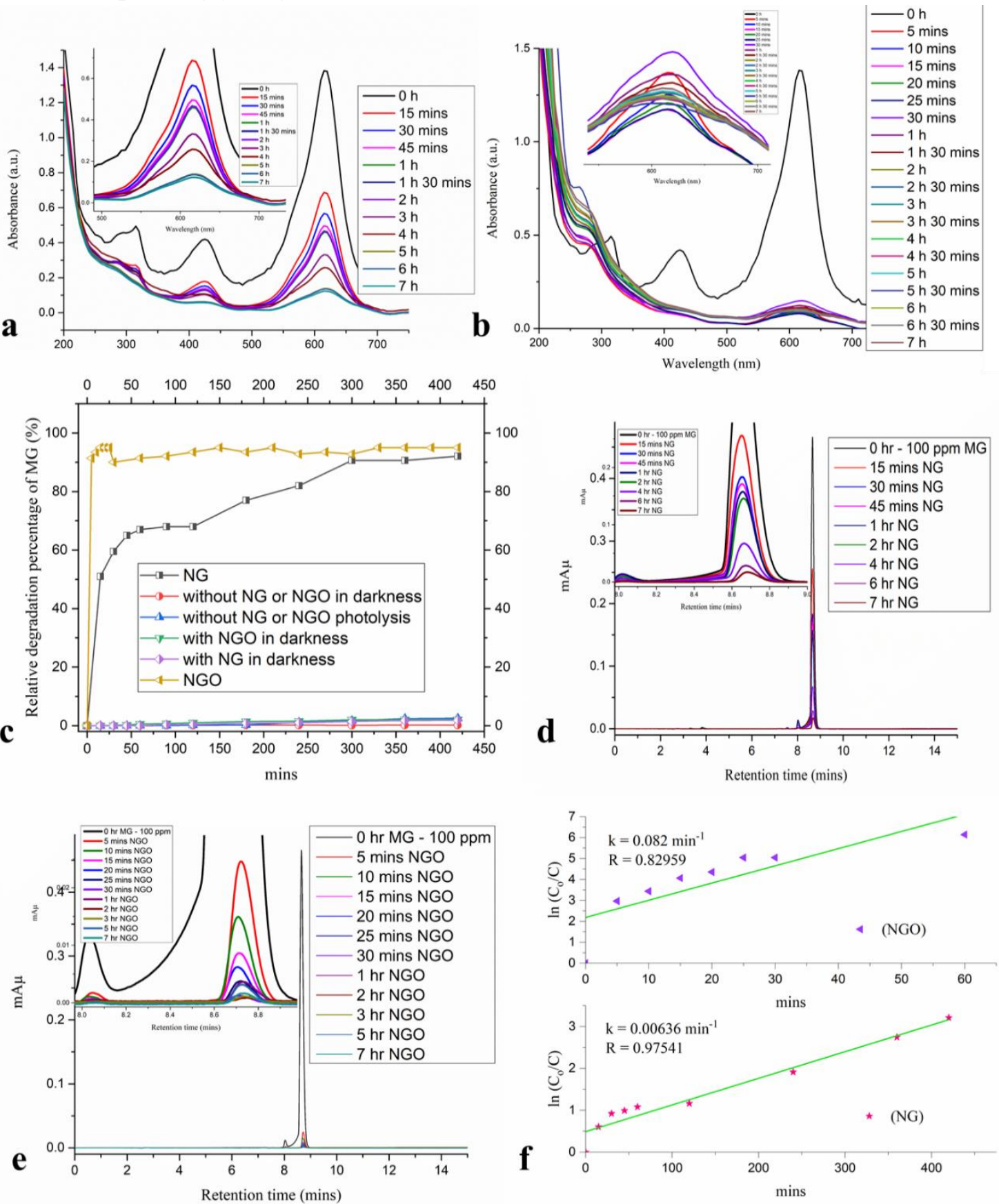

Figure 5. Photodegradation of MG. Absorbance spectra of MG degraded with (a) NG and (b) NGO. (c) Degradation percentage of MG under variable conditions. HPLC of MG degradation by (d) NG and (e) NGO.

(f) Pseudo $1^{\text {st }}$ order kinetics of MG using NG and NGO. 
The r.t. of MG was 8.628 mins at $620 \mathrm{~nm}$ confirmed the rapid photodegradation in the case of NGO as compared to NG. The multiple MG mineralization products started appearing on various wavelengths of the HPLC chromatograms with both NG and NGO @ r.t. 2-4 mins. The pseudo- $1^{\text {st }}$ order rate was deduced with linear fitting slop of $\ln \left(\mathrm{C}_{\mathrm{o}} / \mathrm{C}\right)$ vs. $\mathrm{t}$ was applied for NG and NGO, and the apparent rate constant $(\mathrm{k})$ was found to be 0.00636 and 0.082 $\mathrm{min}^{-1}$, respectively (Figure 5f). The applicability of this kinetics model with NG and NGO was found to be comparable with Pearson's coefficient value (R) of 0.97541 and 0.82959 , respectively [35].
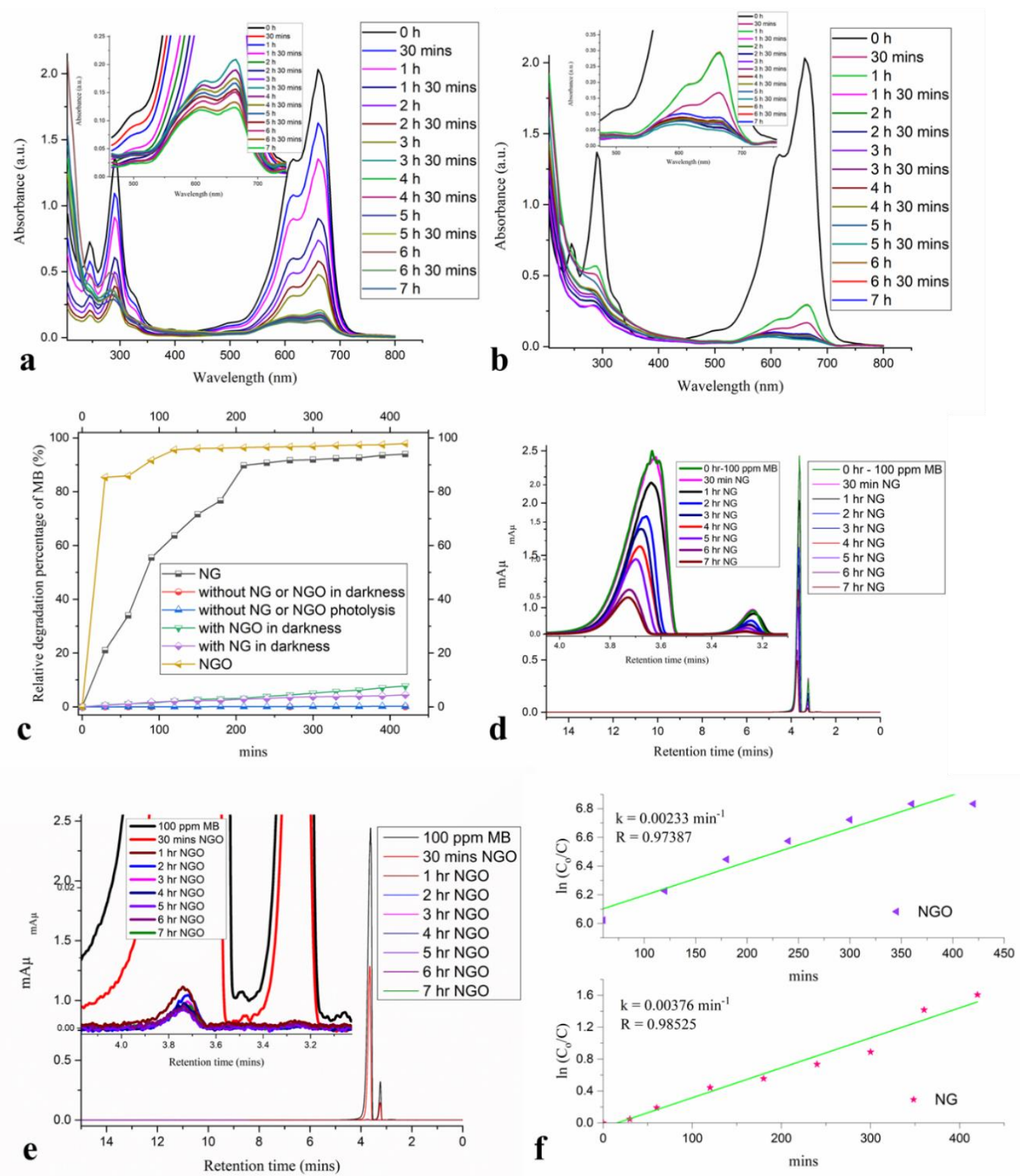

Figure 6. Photodegradation of MB. Absorbance spectra of MB degraded with (a) NG and (b) NGO. (c) Degradation percentage of MB under variable conditions. HPLC of MB degradation by (d) NG and (e) NGO. (f) Pseudo $1^{\text {st }}$ order kinetics of MB using NG and NGO.

In a similar trend, both NG and NGO were found to degrade MB efficiently, which is known to be one of the most carcinogenic industrial effluents. Under visible commercial light, 
MB degraded in the presence of $100 \mathrm{mg}$ of $\mathrm{NG}$ and NGO, separately at neutral $\mathrm{pH}$. In the case of $\mathrm{NG}, \sim 94 \%$ of $\mathrm{MB}$ was decolorized after $7 \mathrm{~h}$ (Figure 6a). However, the relative degradation percentage of MB with NGO was found to be $\sim 97.9 \%$ after $7 \mathrm{~h}$ of exposure under visible light (Figure $6 \mathrm{~b}, \mathrm{c}$ ). The calculations further justified that both NG and NGO didnot facilitate MB degradation under dark conditions showing 4.5 and $7.8 \%$, respectively, within $7 \mathrm{~h}$.

The r.t. of MB @ 662 nm was found to be 3.701 mins upon photodegrading with NG and NGO (Figure 6d, e). The chromatogram of MB degraded with NGO was in good accordance with its corresponding UV-absorbance spectra (inset, Figure 6e). The relative peak area showed a drastic drop in the concentration of MB after $1 \mathrm{~h}$ during degradation with NGO under visible light. The rate kinetics $(\mathrm{k})$ was extrapolated using the pseudo-1st order rate equation (Figure 6f): $\ln \left(\frac{C_{o}}{C}\right)=k t$, where Cois is the initial concentration of $\mathrm{MB}$ and $\mathrm{C}$ is the final concentration of $\mathrm{MB}, \mathrm{k}$ is the apparent rate constant, and $\mathrm{t}$ is the irradiation time. The $\mathrm{k}$ for MB was found to be 0.00376 and $0.00233 \mathrm{~min}^{-1}$, respectively, in the case of NG and NGO. The correlation coefficient $\mathrm{R}$ were 0.98525 and 0.97387 , correspondingly further supported the pseudo-1st order rate kinetics of MB.
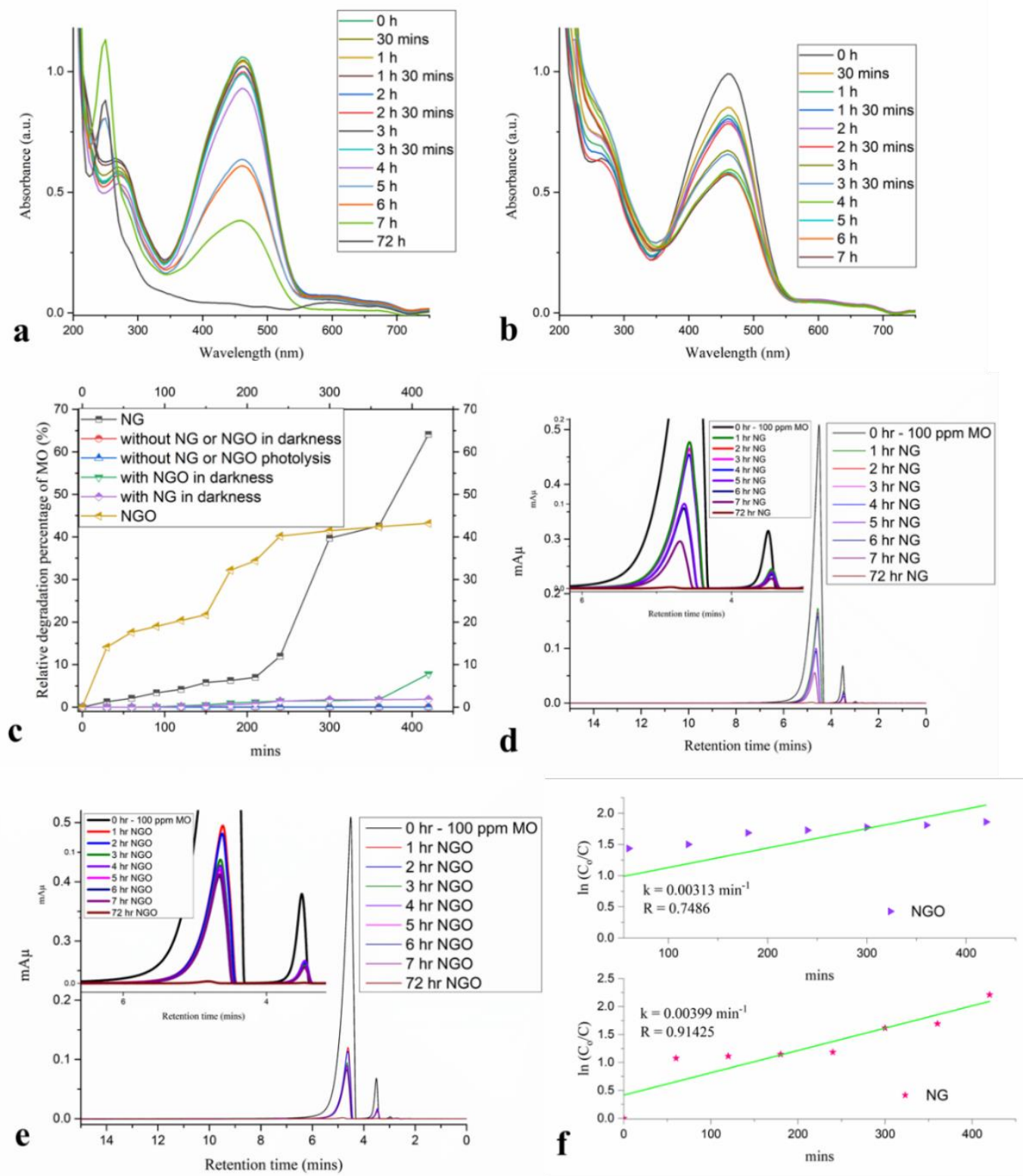
Figure 7. Photodegradation of MO. Absorbance spectra of MO degraded with (a) NG and (b) NGO. (c) Degradation percentage of MO under variable conditions. HPLC of MO degradation by (d) NG and (e) NGO.

(f) Pseudo $1^{\text {st }}$ order kinetics of MO using NG and NGO.

Unlike the photodegradation of MG and MB, MO (azo dye) decolorization proceeded in a sluggish manner for both NG and NGO. The absorbance spectra did not show any remarkable change in dye concentration within the initial $4 \mathrm{~h}$ after degrading with NG (Figure 7a). MO was found to degrade $~ 97.1-99.6 \%$ after long hours (72 h) of irradiation in the case of both NG and NGO (Figure 7b, c). The corresponding HPLC chromatograms @ $503 \mathrm{~nm}$ with r.t. of 4.567 mins supported the UV absorbance spectra of MO degraded with NG and NGO (Figure $7 \mathrm{~d}, \mathrm{e}$ ). The pseudo-1st order rate constant $\mathrm{k}$ was 0.91425 and $0.7486 \mathrm{~min}^{-1}$, respectively, for MO degraded with NG and NGO (Figure 7f).

\subsection{Studies of dye fragments after photodegradation with $N G O$.}

Since photodegradation studies of NGO will be studied in detail against different types of pollutants, so the LC-MS/MS was carried out with NGO only.
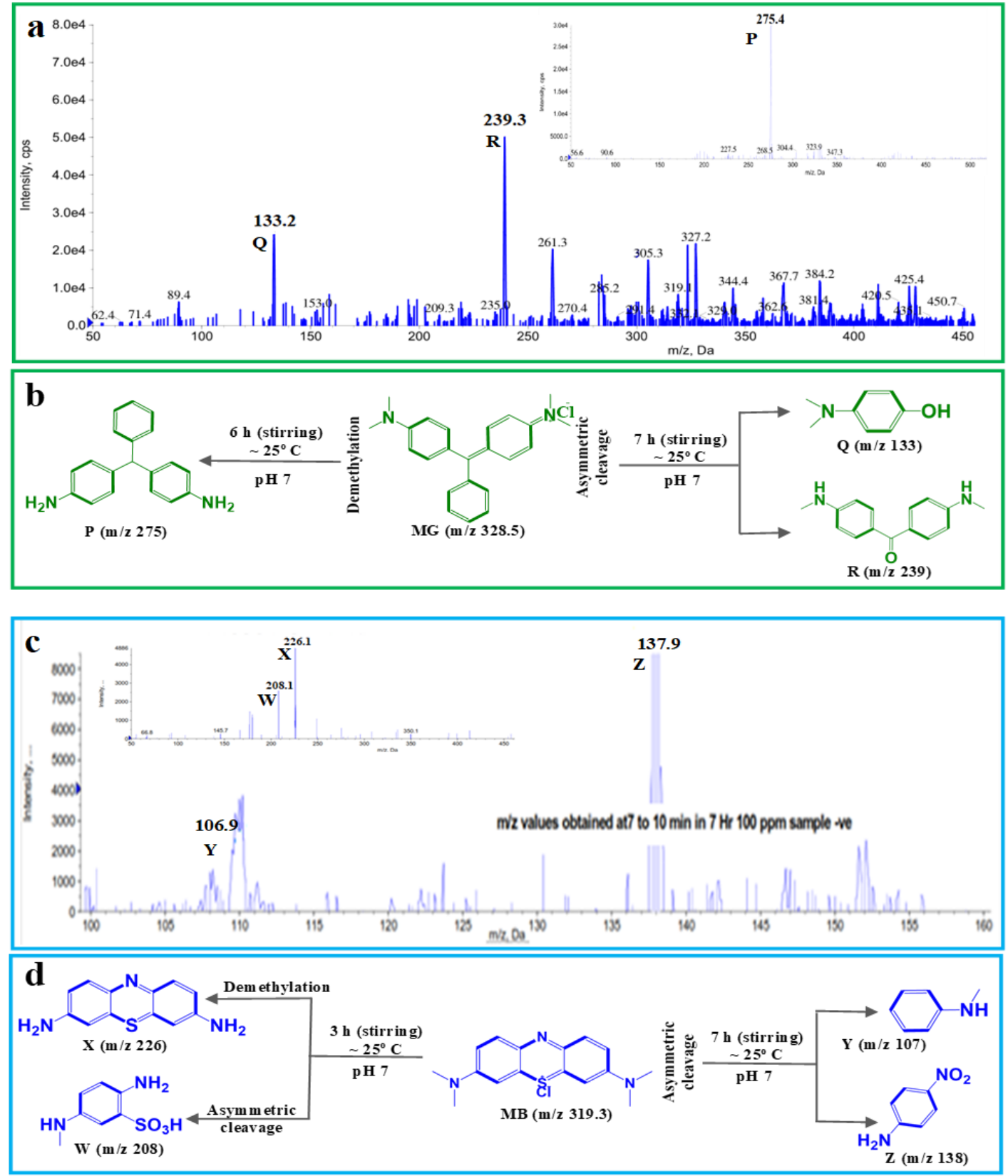
Figure 8. Mass spectra of MG after (a) $7 \mathrm{~h}$ and $6 \mathrm{~h}$ (inset) of stirring with NGO and (b) logical degraded fragments of MG at different time intervals. Mass spectra of MB after (c) $7 \mathrm{~h}$ and $3 \mathrm{~h}$ (inset) of stirring with NGO and (d) logical degraded fragments of MB at different time intervals.

The degraded fragments obtained from various dyes, i.e., MG, MB, and MO, were analyzed by LC-MS/MS and were proposed based on the mass spectral analysis (Figures 8, 9). Initially, in the presence of $\mathrm{NGO}$ at neutral $\mathrm{pH}, 6 \mathrm{~h}$ of stirring under visible light illumination resulted in the photodegradation of $\mathrm{MG}(\mathrm{m} / \mathrm{z} 328.5)$ via demethylation of the terminal methyl $\left(-\mathrm{CH}_{3}\right)$ groups, forming 4,4'-(phenylmethylene) dianiline $(\mathrm{P}, \mathrm{m} / \mathrm{z}=275.4$ [Figure 8a, inset]) as a major product [36]. However, major intermediate products viz. 4-(dimethylamino) phenol $(\mathrm{Q}, \mathrm{m} / \mathrm{z}=133.2)$ and bis(4-(methylamino) phenyl) methanone $(\mathrm{R}, \mathrm{m} / \mathrm{z}=239)$, due to asymmetric cleavage were formed after $7 \mathrm{~h}$ of photodegradation along with multiple minor adducts having $\mathrm{m} / \mathrm{z}>328$ (Figure $8 \mathrm{~b}$ ) [37-39].

In contrast to the photodegradation of MG, NGO generated the fragments free from any adduct products in the case of $\mathrm{MB}$ at neutral $\mathrm{pH}$. The intermediates formed after $3 \mathrm{~h}$ of stirring under visible light in presence of NGO were thionine $(\mathrm{X}, \mathrm{m} / \mathrm{z}=226)$ and 2 -amino-5(methylamino) benzenesulfonic acid $(\mathrm{W}, \mathrm{m} / \mathrm{z}=208$ [Figure 8c, inset]) [40, 41]. The intermediate product $\mathrm{X}$ was formed via demethylation of $\mathrm{MB}$, whereas hydroxyl $\left(\mathrm{OH}^{\circ}\right)$ radical asymmetrically cleaved the MB into fragment $\mathrm{W}$. The complete photodegradation of $\mathrm{MB}$ at neutral $\mathrm{pH}$ after $7 \mathrm{~h}$ resulted in the formation of major molecular peaks i.e., $\mathrm{p}$-nitroaniline ( $\mathrm{Z}$, $\mathrm{m} / \mathrm{z}=138$ ) and $\mathrm{N}$-methylaniline $(\mathrm{Y}, \mathrm{m} / \mathrm{z}=107$ ) (Figure $8 \mathrm{c}$ ) $[42,43]$. The possible asymmetric cleavage pathway suggested that the presence of free $\mathrm{OH}^{\cdot}$ radical might have attacked the pollutant dye molecule or fragment $\mathrm{X}$ resulted in fragments $\mathrm{Y}$ and $\mathrm{Z}$ (Figure 8d).
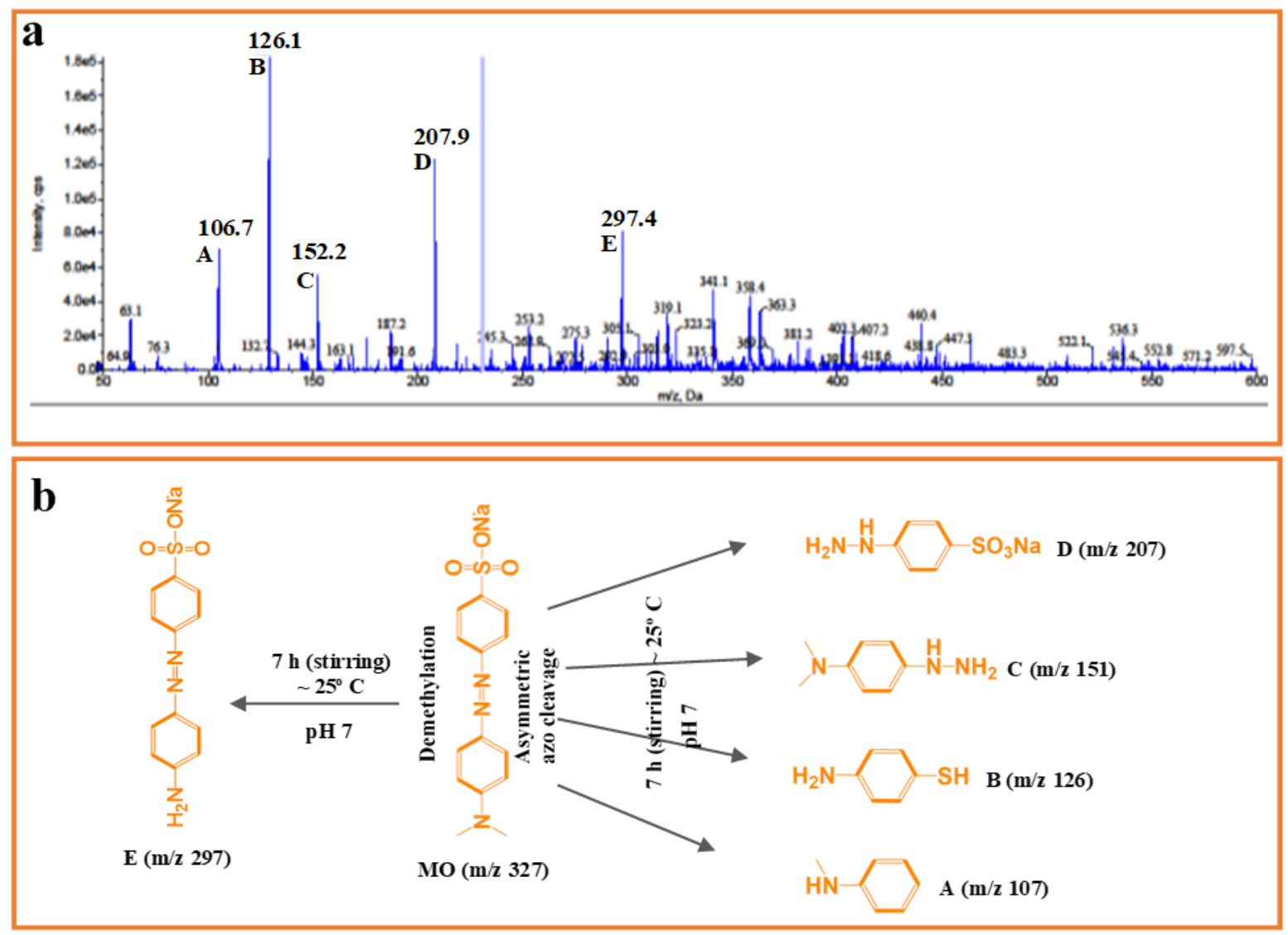

Figure 9.Mass spectra of MO after (a) $7 \mathrm{~h}$ stirring with NGO and (b) logical degraded fragments of MO.

Contrary to fragmentation of MG and MB, $7 \mathrm{~h}$ of stirring with NGO under visible light exposure produced the mass spectra of MO with several multiple adducts having $\mathrm{m} / \mathrm{z}>327$, 
while $6 \mathrm{~h}$ did not show any intense peaks (Figure 9a). Apart from adduct generation, the following major fragments after $7 \mathrm{~h}$ of stirring in presence of NGO were found: $\mathrm{N}$ methylaniline $(\mathrm{A}, \mathrm{m} / \mathrm{z}=107) ; \mathrm{p}$-aminobenzenethiol $(\mathrm{B}, \mathrm{m} / \mathrm{z}=126) ; \mathrm{p}$-hydrazineyl-N,Ndimethylaniline $(\mathrm{C}, \mathrm{m} / \mathrm{z}=151)$; sodium 4-hydrazineylbenzenesulfonate $(\mathrm{D}, \mathrm{m} / \mathrm{z}=207)$ and sodium 4-((4-aminophenyl) diazenyl) benzenesulfonate $(E, m / z=297$ ) (Figure 9b) [44-48]. The formation of several adduct products might have interfered with the photodegradation process leading to a sluggardly degradation rate compared to the photodegradation efficiency of MG and MB, as observed in the UV-vis-absorbance spectra and HPLC chromatograms of $\mathrm{MO}$. Akin to the fragmentation of $\mathrm{MG}$ and $\mathrm{MB}, \mathrm{MO}$ degraded initially to produce fragment $\mathrm{E}$ via demethylation, thus indicating the conversion of $3^{\circ}$ amine into $1^{\circ}$ amine at $\mathrm{pH}$. The presence of $\mathrm{OH}^{\cdot}$ radical in the aqueous solution might form products $\mathrm{C}$ and $\mathrm{D}$ from asymmetric rupture of azo bonds within MO. The other major by-products of MO dye, i.e., A and B, were formed by the demethylation and cleaving or combination of thereof, from $\mathrm{MO}$ or fragment $\mathrm{E}$.

Regardless of the diverse molecular structures of $\mathrm{MG}, \mathrm{MB}$, and $\mathrm{MO}$, the large fragments (mostly $\mathrm{m} / \mathrm{z}>225$ ) of these pollutant dyes occurred initially with demethylation of the terminal $-\mathrm{CH}_{3}$ groups. Similar to the von Braun reaction, herein the aqueous dye solutions catalyzed by NGO displaced $-\mathrm{CH}_{3}$ groups of terminal $3^{\circ}$ amine with hydrogen atoms [49]. The tertiary amine as a first nucleophile displaced the hydroxyl ion, which later acted as the second nucleophile, consequently formed quaternary ammonium salt upon reacting with water under neutral $\mathrm{pH}$ in the presence of NGO (Scheme 2). This $\mathrm{S}_{\mathrm{N}} 2$ reaction might proceed for all the pollutant dyes, knocking methanol as by-products to give 2o followed by 10 amine in the initial fragmentation stage. However, after the complete photodegradation process after $7 \mathrm{~h}$ mass, spectral analysis proved the generation of small fragments occurred via heterolytic cleavage of reactant dyes or large demethylation intermediates of the respective dyes.

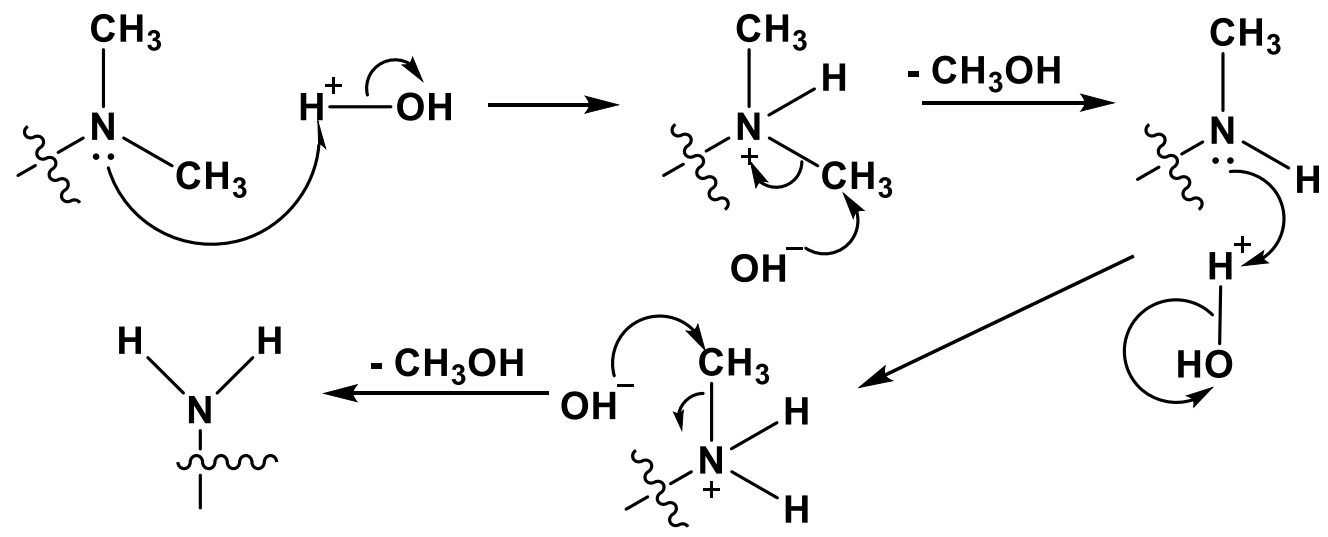

Scheme 2. Proposed demethylation mechanism for MG, MB, and MO.

Amongst all the dyes, MB resembled an anthracene-like structure, and yet it was fragmented feasibly with NG and functionalized NGO. Similarly, the high resonating structure of MG was degraded with both NG and NGO at room temperature under the influence of visible light. The structure of MO enabled cleaving at any possible position with NGO, and hence several adducts were formed. This indicated both NG and NGO had immense potential to degrade bulky pollutant molecular structures with high resonance such as MB, MG, and MO.

\subsection{Real-time practical application and cultivation of aquatic plants.}

In the case of dye cocktail (1:1:1 ratio of MG:MB:MO), it was found that NGO had promising photodegrading ability than NG, and the separation of three dyes in HPLC showed 
most prominent peaks at $550 \mathrm{~nm}$ (Figure 10a). The photodegradation of MB occurred much rapidly with a drastic fall in the initial concentration as well as degradation efficiency reached over $\sim 98.2 \%$ within $1 \mathrm{~h}$ on treating with NGO.
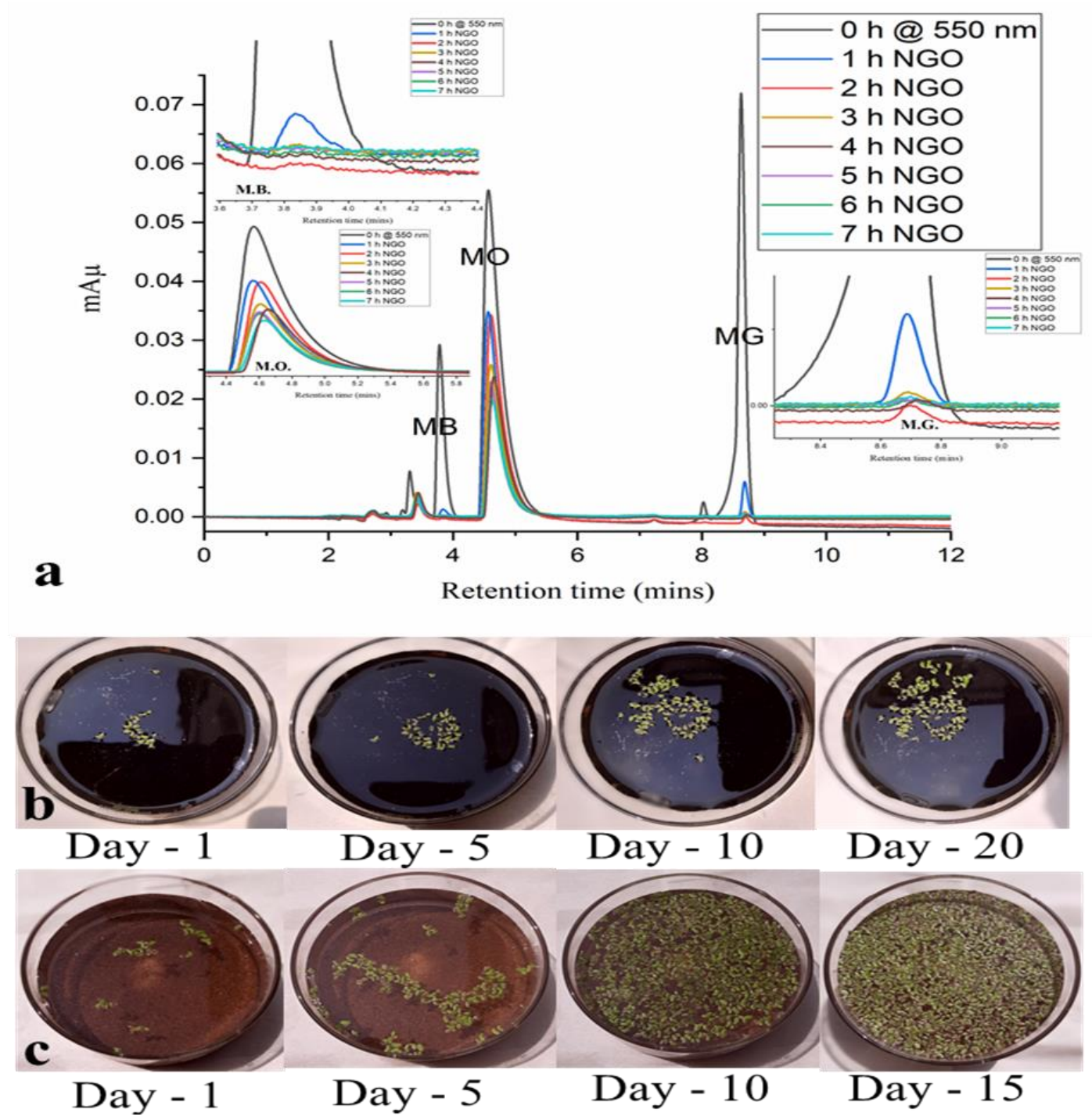

Figure 10.(a) HPLC of dye mixtures degraded with NGO. Photographs depicting the growth of Common Duckweed in (b) dye cocktail comprising of three dyes and (c) treated water after $7 \mathrm{~h}$ of photodegradation reaction using NGO.

Similarly, the usage of NGO enabled threshold photodegradation of MG within the initial $1 \mathrm{~h}$ of the reaction with efficiency over $\sim 98 \%$. Hence, this proved NGO had immense potential as a photocatalyst to decolorize highly resonance stabilized structures like MB and MG. However, in contrast to the photodegradation of MB and MG, the breakdown of MO was comparatively less with NGO, and the degradation efficiency attained $\sim 70 \%$ after $7 \mathrm{~h}$ of stirring under visible light illumination. Although degradation of $\mathrm{MO}$ was comparatively slow with respect to the irradiation time of the other two pollutant dyes, the degradation of MO carried out in dye mixture was rapid than MO used as a sole dye degraded with NGO. The oxidizing fragments generated from other dyes upon reacting with NGO might enhance the degradation rate and help fragment MO quicker than solitary degradation of MO with NGO. Lemna minor has extensive phytoremediation quality to adsorb heavy metals in stagnant fresh water; however, their growth was severely hampered during the in-vitro study in dye mixtures [50-54]. Hence, to ensure the capability of NGO in promoting sustainable growth against Lemna minor, a comparative study was performed against the same dye mixture and NGO- 
treated water up to $7 \mathrm{~h}$ (Figure 10b, c). In the case of the dye mixture, no substantial growth was observed even up to the 20th day. However, the dye mixture treated with NGO was found to show eximious rapid growth of this aquatic weed within 15 days.

\section{Conclusions}

3-aminophenol can also produce nanosheets of $\mathrm{N}$-graphene (NG) in the presence of urea at the temperature of $120-125^{\circ} \mathrm{C}$, which prevented the attack of atmospheric oxygen. It was observed that both NG and nitrogen-containing graphene oxide (NGO) had immense potential to degrade the highly resonance stabilized dyes viz. MG, MB, and MO with degradation efficiency reaching $\geq 92 \%$. Despite non-functionalized NG, the presence of nitrogen within the graphenic lattice and keto groups in the side lattice facilitated effective photodegradation against all the pollutant dyes. Whereas $-\mathrm{OH},-\mathrm{NH}_{2}, \mathrm{C}=\mathrm{O}$ within the functionalized NGO enhanced the rate of photodegradation as well as strengthened the degradation efficacy. Further LC-MS/MS analysis confirmed that NGO was capable of breaking the dyes' complex structures via demethylation and asymmetric cleaving at neutral $\mathrm{pH}$. Fascinatingly, NGO was found to show excellent photodegradation results against the dye cocktail (1:1:1 ratio of $\mathrm{MG}, \mathrm{MB}$, and $\mathrm{MO}$ ), which was confirmed by real-time application against in-vitro growth of Lemna minor. This mixture did not show any significant growth of Lemna minor within 20 days. However, the NGO-treated dye mixture resulted in its rapid growth within 15 days.

\section{Funding}

This work was self-funded by the authors.

\section{Acknowledgments}

The authors like to thank the Central Research Facility (CRF) of NIT Agartala for the XRD pattern, Indian Institute of Science Education \& Research - Kolkata for STEM-HAADF and HRTEM analysis. The EDX analyses and Raman spectroscopy for one-step N-graphene were performed in Tripura University and Central Glass \& Ceramic Research Institute - Kolkata. The photodegradation studies involving UV-Vis Spectrophotometer and HPLC were performed in the Department of Veterinary Pharmacology \& Toxicology, West Bengal University of Animal \& Fishery Sciences, Kolkata. The authors are highly obligated to Kris Biotech Research Pvt. Ltd., Kalyani, for LC-MS analysis of the dye fragments.

\section{Conflicts of Interest}

The authors declare no conflict of interest.

\section{References}

1. Kumar, R.; Sankhla, M.S.; Kumar, R.; Sonone, S.S. Impact of Pesticide Toxicity in Aquatic Environment. Biointerface Res. Appl. Chem. 2021, 11, 10131-10140, https://doi.org/10.33263/BRIAC113.1013110140.

2. Kit, N.H.;Hadibarata, T.; Yuniarto, A.; Sari, A.A.,Removal of triphenylmethane dye from aqueous solutions through an adsorption process over waste materials.Biointerface Res. Appl. Chem. 2020, 10, $5772-$ 5779,https://doi.org/10.33263/BRIAC104.772779. 
3. Mohan, H.; Rajput, S.S.; Jadhav, E.B.; Sankhla, M.S.; Sonone, S.S.; Jadhav, S.; Kumar, R. Ecotoxicity, Occurrence, and Removal of Pharmaceuticals and Illicit Drugs from Aquatic Systems. Biointerface Res. Appl. Chem.2021, 11, 12530-12546, https://doi.org/10.33263/BRIAC115.1253012546.

4. Shindhal, T.; Rakholiya, P.; Varjani, S.; Pandey, A.; Ngo, H. H.; Guo, W.; Ng, H. Y.; Taherzadeh, M. J. A critical review on advances in the practices and perspectives for the treatment of dye industry wastewater. Bioengineered 2021,12, 70-87, https://doi.org/10.1080/21655979.2020.1863034.

5. Yeow, P.K.; Wong, S.W.; Hadibarata, T. Removal of azo and anthraquinone dye by plant biomass as adsorbent-a review. Biointerface Res. Appl. Chem.2021, 11, 8218-8232, https://doi.org/10.33263/BRIAC111.82188232.

6. Mohanta, J.; Dey, B.; Dey, S. Magnetic Cobalt Oxide Nanoparticles: Sucrose-Assisted Self-Sustained Combustion Synthesis, Characterization, and Efficient Removal of Malachite Green from Water. J. Chem. Eng. Data 2020,65, 2819-2829, https://doi.org/10.1021/acs.jced.0c00131.

7. Taran, M.; Safaei, M.; Karimi, N.; Almasi, A. Benefits and application of nanotechnology in environmental science: an overview. Biointerface Res. Appl. Chem.2021, 11, 7860-7870, https://doi.org/10.33263/BRIAC111.78607870.

8. Mandal, P.; Saha, M. Synthesis of Graphene Nanosheets and Photocatalytic Application in Dye Degradation. J. Sci. Ind. Res. 2019,78, 863-867, http://nopr.niscair.res.in/handle/123456789/52214.

9. Ali, I.; Burakova, I.; Galunin, E.; Burakov, A.; Mkrtchyan, E.; Melezhik, A.; Kurnosov, D.; Tkachev, A.; Grachev, V. High-speed and high-capacity removal of methyl orange and malachite green in water using newly developed mesoporous carbon: kinetic and isotherm studies. ACS Omega 2019,4, 19293-19306, https://doi.org/10.1021/acsomega.9b02669.

10. Quan, Y.; Shi, W.; Song, Y.; Jiang, X.; Wang, C.; Lin, W. Bifunctional Metal-Organic Layer with Organic Dyes and Iron Centers for Synergistic Photoredox Catalysis. J. Am. Chem. Soc. 2021,143, 3075-3080, https://doi.org/10.1021/jacs.1c01083.

11. Latif, A.F.A.; Yee, L.S.; Muhamad, M.S.; Te Chuan, L.; Basri, H. Natural Adsorbent Made from Eggshells for Removal of Chromium (VI) in Water.Biointerface Res. Appl. Chem, 2022, 12, 518528,https://doi.org/10.33263/BRIAC121.518528.

12. Khairy, M.; Kamar, E.M.; Yehia, M.; Masoud, E.M. High Removal Efficiency of Methyl Orange Dye by Pure and $(\mathrm{Cu}, \mathrm{N})$ Doped TiO2/Polyaniline Nanocomposites.Biointerface Res. Appl. Chem, 2022, 12, 893909, https://doi.org/10.33263/BRIAC121.893909.

13. Ge, X.; Zhou, P.; Zhang, Q.; Xia, Z.; Chen, S.; Gao, P.; Zhang, Z.; Gu, L.; Guo, S. Palladium single atoms on $\mathrm{TiO} 2$ as a photocatalytic sensing platform for analyzing the organophosphorus pesticide chlorpyrifos. Angew. Chem. 2020,132, 238-242, https://doi.org/10.1002/ange.201911516.

14. Sharma, M.; Vaish, R. Piezo/pyro/photo-catalysis activities in Ba0. 85Ca0. 15 (Ti0. 9Zr0. 1) 1-xFexO3 ceramics. J. Am. Ceramic Soc.2021, 104, 45-56, https://doi.org/10.1111/jace.17417.

15. Sehar, S.; Naz, I.; Rehman, A.; Sun, W.; Alhewairini, S. S.; Zahid, M. N.; Younis, A. Shape-controlled synthesis of cerium oxide nanoparticles for efficient dye photodegradation and antibacterial activities. Appl. Organomet. Chem. 2021,35, e6069, https://doi.org/10.1002/aoc.606910.

16. Al Aqad, K. M.; Basheer, C. Photocatalytic degradation of basic blue dye using zinc nanoparticles decorated graphene oxide nanosheet. J. Phys. Org. Chem. 2021,34, e4117, https://doi.org/10.1002/poc.4117.

17. Dan, S.; Upadhyay, S.K.; Pant, M. Synergistic Approach of Graphene Oxide-Silver-Titanium Nanocomposite Film in Oral and Dental Studies: A New Paradigm of Infection Control in Dentistry. Biointerface Res. Appl. Chem.2021, 11, 9680-9703,https://doi.org/10.33263/BRIAC112.96809703.

18. Gao, J.; Shen, Y.; Fang, J.; Zhu, W.; Lin, X.; Song, H.; Zhang, S.; Wang, X. Heterojunctions Derived by Integrating Arylene-Ethynylene Nanobelts and N-Doped Graphene for Molecular Sensing. ACS Appl. Nano Mater. 2019,2, 2336-2346, https://doi.org/10.1021/acsanm.9b00227.

19. Dong, X. Y. M.; Li, Y. Y.; Li, S. H.; Wang, Y.; Zhu, J. H. Insight into the CO2 capturer derived from graphene/MgO composite. CLEAN-Soil, Air, Water 2017,45, 1600755, https://doi.org/10.1002/clen.201600755.

20. Fávaro, W.J.; de Souza, J.G.; Matsumoto, M.Y.; Durán, M.; Bockelmann, P.K.; Dias, Q.C.; Durán, N. Associating Graphene Oxide Derivatives to Treat Non-Muscle Invasive Bladder Cancer (NMIBC).Biointerface Res. Appl. Chem. 2022, 12, 196-210,https://doi.org/10.33263/BRIAC121.196210.

21. Zhu, W.; Gao, J.; Song, H.; Lin, X.; Zhang, S. Nature of the synergistic effect of N and S Co-Doped graphene for the enhanced simultaneous determination of toxic pollutants. ACS Appl. Mater. Interfaces 2019,11, 44545-44555, https://doi.org/10.1021/acsami.9b13211. 
22. Ali, I.; Alharbi, O. M.; Tkachev, A.; Galunin, E.; Burakov, A.; Grachev, V. A. Water treatment by newgeneration graphene materials: hope for bright future. Environ. Sci. Pollut. Res. 2018,25, 7315-7329, https://doi.org/10.1007/s11356-018-1315-9.

23. Li, X.; Liu, T.; Wang, D.; Li, Q.; Liu, Z.; Li, N.; Zhang, Y.; Xiao, C.; Feng, X. Superlight adsorbent sponges based on graphene oxide cross-linked with poly (vinyl alcohol) for continuous flow adsorption. ACS Appl. Mater. Interfaces 2018,10, 21672-21680, https://doi.org/10.1021/acsami.8b06802.

24. Mandal, P.; Debbarma, J.; Saha, M., A Review on the Emergence of Graphene in Photovoltaics $\begin{array}{lllll}\text { Industry.Biointerface } \quad \text { Res. } & \text { Appl. } & \text { Chem2021, } & \text { 11, }\end{array}$ 15036,https://doi.org/10.33263/BRIAC116.1500915036.

25. Li, Z.-J.; Huang, Z.-W.; Guo, W.-L.; Wang, L.; Zheng, L.-R.; Chai, Z.-F.; Shi, W.-Q. J. Enhanced photocatalytic removal of uranium (VI) from aqueous solution by magnetic $\mathrm{TiO} 2 / \mathrm{Fe} 3 \mathrm{O} 4$ and its graphene composite. Environ. Sci. Technol. 2017,51, 5666-5674, https://doi.org/10.1021/acs.est.6b05313.

26. Mandal, P.; Debbarma, J.; Saha, M. One Step Synthesis of N-Containing Graphene Oxide from 3Aminophenol. Cryst. Res. Technol. 2020,55, 1900158, https://doi.org/10.1002/crat.201900158.

27. Mandal, P.;Naik, M.J.P.; Saha, M. Room temperature synthesis of graphene nanosheets. Cryst Res. Technol. 2018, 53, 1700250, https://doi.org/10.1002/crat.201700250.

28. Mandal, P.; Saha, M. Low-temperature synthesis of graphene derivatives: mechanism and characterization. Chem. Pap. 2019,73, 1997-2006, https://doi.org/10.1007/s11696-019-00756-3.

29. Mandal, P.; Saha, M. Scalable preparation of carbon nanoparticles and graphene nanoflakes using sand paper abrasion. Materialwiss. Werkst.2020, 51, 902-907, https://doi.org/10.1002/mawe.201900135.

30. Tuinstra, F.; Koenig, J. L. Raman spectrum of graphite. J. Chem. Phys. 1970,53, 1126-1130, https://doi.org/10.1063/1.1674108.

31. Chastain, J.; King Jr, R. C. Handbook of X-ray photoelectron spectroscopy. Perkin-Elmer Corporation: Eden Prairie, USA, 1992;40, p 221.

32. Sadatmansouri, E.; Shahrnoy, A.A.; Mahjoub, A.R., Competitive photocatalytic activity of ionic crystal decorated magnetic graphene oxide/cobalt monoxide nanocomposite: Comparison to its MWCNTs analogue. Diam. Relat. Mater.2021, 111, 108209, https://doi.org/10.1016/j.diamond.2020.108209.

33. Mandal, P.; Nath, K.K.; Saha, M. Efficient Blue Luminescent Graphene Quantum Dots and their Photocatalytic Ability Under Visible Light. Biointerface Res. Appl. Chem2021, 11, 8171-8178, https://doi.org/10.33263/BRIAC111.81718178.

34. Yeh, T.-F.; Cihlář, J.; Chang, C.-Y.; Cheng, C.; Teng, H. Roles of graphene oxide in photocatalytic water splitting. Mat. Today 2013,16, 78-84, https://doi.org/10.1016/j.mattod.2013.03.006.

35. Egghe, L.; Leydesdorff, L., The relation between Pearson's correlation coefficient $r$ and Salton's cosine measure. J. Am. Soc. Inf. Sci. Technol. 2009,60, 1027-1036, https://doi.org/10.1002/asi.21009.

36. Ray, S. K.; Dhakal, D.; Lee, S. W. Insight Into Malachite Green Degradation, Mechanism and Pathways by Morphology-Tuned $\alpha$-NiMoO4 Photocatalyst. Photochem. Photobiol. 2018,94, 552-563, https://doi.org/10.1111/php.12872.

37. Ju, Y.; Yang, S.; Ding, Y.; Sun, C.; Gu, C.; He, Z.; Qin, C.; He, H.; Xu, B. Microwave-enhanced H2O2-based process for treating aqueous malachite green solutions: intermediates and degradation mechanism. J. Hazard. Mater. 2009,171, 123-132, https://doi.org/10.1016/j.jhazmat.2009.05.120.

38. Ju, Y.; Yang, S.; Ding, Y.; Sun, C.; Zhang, A.; Wang, L. Microwave-assisted rapid photocatalytic degradation of malachite green in TiO2 suspensions: mechanism and pathways. J. Phys. Chem. A 2008,112, 11172-11177, https://doi.org/10.1021/jp804439z.

39. Pérez-Estrada, L.; Agüera, A.; Hernando, M.; Malato, S.; Fernández-Alba, A. Photodegradation of malachite green under natural sunlight irradiation: kinetic and toxicity of the transformation products. Chemosphere 2008,70, 2068-2075, https://doi.org/10.1016/j.chemosphere.2007.09.008.

40. Krishnan, S.; Shriwastav, A.Application of $\mathrm{TiO} 2$ nanoparticles sensitized with natural chlorophyll pigments as catalyst for visible light photocatalytic degradation of methylene blue. J. Environ. Chem. Eng. 2021,9, 104699, https://doi.org/10.1016/j.jece.2020.104699.

41. Ghaffari, M.; Tan, P. Y.; Oruc, M. E.; Tan, O. K.; Tse, M. S.; Shannon, M. Effect of ball milling on the characteristics of nano structure $\mathrm{SrFeO} 3$ powder for photocatalytic degradation of methylene blue under visible light irradiation and its reaction kinetics. Catal. Today 2011,161, 70-77, https://doi.org/10.1016/j.cattod.2010.11.031. 
42. Zhao, Y.; Zhang, Y.; Liu, A.; Wei, Z.; Liu, S. Construction of three-dimensional hemin-functionalized graphene hydrogel with high mechanical stability and adsorption capacity for enhancing photodegradation of methylene blue. ACS Appl. Mater. Interfaces 2017,9, 4006-4014, https://doi.org/10.1021/acsami.6b10959.

43. Li, K.; Luo, X.; Lin, X.; Qi, F.; Wu, P. Novel NiCoMnO4 thermocatalyst for low-temperature catalytic degradation of methylene blue. J. Mol. Catal. A Chem. 2014,383, 1-9, https://doi.org/10.1016/j.molcata.2013.11.017.

44. Ghattavi, S.; Nezamzadeh-Ejhieh, A. GC-MASS detection of methyl orange degradation intermediates by AgBr/g-C3N4: Experimental design, bandgap study, and characterization of the catalyst. Int. J. Hydrog. Energy 2020,45, 24636-24656, https://doi.org/10.1016/j.ijhydene.2020.06.207.

45. He, Y.; Grieser, F.; Ashokkumar, M. The mechanism of sonophotocatalytic degradation of methyl orange and its products in aqueous solutions. Ultrason. Sonochem. 2011,18, 974-980, https://doi.org/10.1016/j.ultsonch.2011.03.017.

46. Bilal, M.; Rasheed, T.; Iqbal, H. M.; Hu, H.; Wang, W.; Zhang, X. Novel characteristics of horseradish peroxidase immobilized onto the polyvinyl alcohol-alginate beads and its methyl orange degradation potential. Int. J. Biol. Macromol. 2017,105, 328-335, https://doi.org/10.1016/j.ijbiomac.2017.07.042.

47. Chen, Y.-P.; Liu, S.-Y.; Yu, H.-Q.; Yin, H.; Li, Q.-R.Radiation-induced degradation of methyl orange in aqueous solutions. Chemosphere 2008,72, 532-536, https://doi.org/10.1016/j.chemosphere.2008.03.054.

48. Kaur, J.; Singhal, S. Facile synthesis of $\mathrm{ZnO}$ and transition metal doped $\mathrm{ZnO}$ nanoparticles for the photocatalytic degradation of Methyl Orange. Ceramics Int. 2014,40, 7417-7424, https://doi.org/10.1016/j.ceramint.2013.12.088.

49. Leonard, N. J.; Nommensen, E. W. Studies on the mechanism of the Von Braun reaction. J. Am. Chem. Soc. 1949,71, 2808-2813, https://doi.org/10.1021/ja01176a062.

50. Liu, Y.; Xu, H.; Yu, C.; Zhou, G. Multifaceted roles of duckweed in aquatic phytoremediation and bioproducts synthesis. GCB Bioenergy,2021, 13, 70-82, https://doi.org/10.1111/gcbb.12747.

51. Jmii, S.; Dewez, D. Toxic Responses of Palladium Accumulation in Duckweed (Lemna minor): Determination of Biomarkers. Environ. Toxicol. Chem.2021, 40, 16301638,https://doi.org/10.1002/etc.5011.

52. Sarkheil, M.; Safari, O. Phytoremediation of nutrients from water by aquatic floating duckweed (Lemna minor) in rearing of African cichlid (Labidochromis lividus) fingerlings. Environ. Technol. Inno. 2020, 18, 100747, https://doi.org/10.1016/j.eti.2020.100747.

53. Ekperusi, A. O.; Sikoki, F. D.; Nwachukwu, E. O. Application of common duckweed (Lemna minor) in phytoremediation of chemicals in the environment: State and future perspective. Chemosphere 2019,223, 285-309, https://doi.org/10.1016/j.chemosphere.2019.02.025.

54. Miretzky, P.; Saralegui, A.; Cirelli, A. F. Simultaneous heavy metal removal mechanism by dead macrophytes. Chemosphere 2006,62, 247-254, https://doi.org/10.1016/j.chemosphere.2005.05.010. 